\title{
Should embolectomy be performed in late acute lower extremity arterial occlusions?
}

\author{
This article was published in the following Dove Press journal: \\ Vascular Health and Risk Management \\ 29 July 2009 \\ Number of times this article has been viewed
}

\author{
Hikmet lyem \\ M Nesimi Eren \\ Department of Cardiovascular \\ Surgery, Dicle University, Diyarbakir, \\ Turkey
}

Background: We analyzed the embolectomy results and complications of patients who were operated on after a diagnosis of late acute arterial occlusion of lower extremities.

Methods: A total of 122 patients operated on in our clinic between 2004 and 2009 for late acute arterial occlusion were included in the study. Late arterial occlusion was defined as occlusion occuring 72 hours after initial manifestation of the patient complaints related to the affected lower extremity.

Results: Average age of the 122 patients (71 male, 51 female) was $54.2 \pm 16.8$ years. In this cohort, $64.75 \%$ of patients had cardiac pathologies, while $28.68 \%$ had extracardiac causes; $1.64 \%$ patients had cathetherization, $0.81 \%$ patient had malignancy, and $2.46 \%$ patients had a history of trauma. In $1.64 \%$ of the cases, no reason for thromboembolysis could be found. Thirty-one patients (25.40\%) had additional surgical operations, 14 (11.47\%) had fasciotomy, and 9 (7.37\%) had amputation. Re-embolectomy was performed on 37 patients $(30.32 \%)$ who had ongoing ischemia after an operation. Additional surgical operations were performed on 31 patients $(25.40 \%)$ with ongoing ischemia. In 14 of these cases (11.47\%), patients were treated with fasciotomy due to development of compartment syndrome. Amputation was performed on a total of 9 patients. Early in the postoperative phase, mortality was observed in 11 patients $(9.01 \%)$.

Conclusion: We believe that late embolectomies of acute late leg ischemia increases blood flow in the extremity and reduces the number of amputations required.

Keywords: lower extremity, embolism, prognosis, treatment outcome

\section{Introduction}

Critical leg ischemia can be observed as an acute event that is either the initial finding of peripheral arterial disease for a patient or the reason for symptomatic deterioration in a patient with peripheral arterial disease of the lower extremities (intermittent claudication). Since some cells are more sensitive to anoxia, it is very difficult to determine the tolerance of extremities to ischemia. After 4 to 6 hours of ischemia, irreversible changes arise in skeletal muscles and peripheral nerves.

In acute arterial occlusive disease, rapid diagnosis and performing the appropriate treatment with a multidisciplinary approach are critically important. Nevertheless, despite the progress in treatment and techniques, amputation and mortality rates have remained high, even in special/private vascular surgery centers. ${ }^{1}$ Late use of embolectomy on an extremity with ischemia remains controversial, but has been gaining acceptance.

It is known that a delay of more than 8 hours increases ischemic complications in patients with arterial emboli in an extremity. On the other hand, the literature
Correspondence: Hikmet lyem Dicle Üniversitesi Kalp Damar Cerrahis AD/Diyarbakir/Turkey

$\mathrm{Tel}+904$ I 248800 I

Fax +90 4I 248802I

Email hikmetiyem@gmail.com 
shows a decrease in appearance of complications when the period of ischemia exceeds 7 days. ${ }^{2}$ In light of this observation, it can be inferred that performance of a surgical operation after the patient has survived the first week of ischemia with little extremity or tissue loss could be more successful. In this clinical study, our aim was to analyze retrospectively the results of arterial embolectomies and complications in patients, who are admitted to surgery with diagnosis of late acute lower extremity arterial occlusion.

\section{Materials and methods}

A total of 122 patients who were admitted to our clinic with diagnosis of late acute lower extremity arterial occlusion and who were operted on between January 2004 and February 2009 were included in the study. Computer records of these patients were retrospectively analyzed and recorded.

Late arterial occlusion is defined as occlusion occuring 72 hours after initial manifestation of patient complaints related to the effected lower extremity. Only the patients who met this criterion were included in this study. We excluded the patients with polytrauma because we thought that it may negatively affect mortality and morbidity. In all cases, diagnosis was made by the use of anamnesis, physical examination, and doppler ultrasonography; we employed no additional tests, such as conventional angiography or CT angiography, to any patients prior to surgery. No intraoperative angiography was performed on any patient, but all patients duplex examiniation was performed on all patients in the preoperative period.

When examining the patients, we sought answers to three questions: is the extremity still viable? Is the viability of the extremity acutely threatened? Are there irreversible changes that hinder preservation of the extremity? All of the patients were analyzed according to the Turkish Society of Vascular Surgery classification scheme (Table 1). ${ }^{3}$ Nonetheless, we performed advanced tests on those patients whose ischemia were not treated with embolectomy and who had planned reoperations. After embolectomy, all the patients were examined with abdominal ultrasonography and cardiac ecocardiography to investigate the origin of the arterial occlusion.

\section{Surgical method}

Femoral arterial embolectomies of the lower extremities were performed under local anesthesia by a longitudinal incision from the femoral region. Spinal anesthesia was used for patients that had popliteal embolectomy and additional surgical operation. Standard $3 \mathrm{~F}, 4 \mathrm{~F}$ and $5 \mathrm{~F}$ Fogarty embolectomy catheters were used. 3F and 4F Fogarty catheters were used for distal embolectomy while 5F Fogarty catheters were used for proximal embolectomy.

The embolectomy was stopped when the thrombus was completely removed from distal and proximal approaches (when the thrombus could not be contacted distally or proximally by a Fogarty catheter), and distal backflow and proximal flow was deemed adequate. In all cases, arteriotomy was closed by washing the distal bed with $5000 \mathrm{U}$ of heparin diluted in $100 \mathrm{~mL}$ of $0.9 \%$ physiological saline solution. For patients with ongoing ischemia despite embolectomy, additional surgery was performed after CT angiography or conventional angiography (Table 2).

\section{Preoperative and postoperative medical treatment protocol}

For all patients diagnosed with arterial occlusion, heparindextran 40-pentoxyphillin infusion was administered and continued for 3 days postoperatively. Conventional heparin was started at a dose of $100 \mathrm{U} / \mathrm{kg} / \mathrm{h}$ and dextran 40 at $0.5 \mathrm{~mL} / \mathrm{kg} / \mathrm{h}$. Heparin was assessed with ACT (activated coagulation time). ACT level was maintained within the range of 200 to 300 seconds. Following this, patients were administered anticoagulants.

\section{Statistical analysis}

SPSS Windows 10.0 statistical software package was used for analyzing patient records. Continuous variables are presented as means \pm standard deviation. Student's test, Chi-square

Table I Assessment of viability of the extremity

\begin{tabular}{|c|c|c|c|c|c|}
\hline & $\begin{array}{l}\text { Description/ } \\
\text { Prognosis }\end{array}$ & Sensory loss & $\begin{array}{l}\text { Functional failure } \\
\text { in muscle }\end{array}$ & $\begin{array}{l}\text { Arterial doppler } \\
\text { signals }\end{array}$ & $\begin{array}{l}\text { Venous doppler } \\
\text { signals }\end{array}$ \\
\hline Stage I: Viable & No urgent threat & No & No & Yes & Yes \\
\hline Stage 2a: Marginal threat & Can be saved & Minimal (fingers) & No & Yes & Yes \\
\hline Stage 2b: Serious threat & Can be saved urgently & Extensive & Mild-moderate & No & Yes \\
\hline Stage 3: Irreversible & Inevitable tissue loss & Anesthesia & Paralysis & No & No \\
\hline
\end{tabular}


Table 2 Surgical operations and occlusion levels

\begin{tabular}{lll}
\hline & N & $\%$ \\
\hline Surgical operations & 88 & 72.13 \\
Femoral embolectomy & 21 & 17.21 \\
Popliteal embolectomy & 13 & 10.65 \\
Femoral + popliteal embolectomy & & \\
Additional surgical operations & 7 & 5.73 \\
Aortafemoral bypass & 5 & 4.09 \\
Iliofemoral bypass & 7 & 5.73 \\
Femorofemoral bypass & 12 & 9.83 \\
Femoropopliteal bypass & & \\
Occlusion level & 7 & 5.73 \\
Aortic bifurcation & 12 & 9.83 \\
Iliac & 78 & 63.93 \\
Femoral & 25 & 20.49 \\
\hline Popliteal & & \\
\hline
\end{tabular}

and Fisher's exact tests were used. A $P$ value $<0.05$ was considered as statistically significant.

\section{Results}

Average age of the 122 patients ( 71 male, 51 female) operated on was $54.2 \pm 16.8$ years. Preoperative demographic data of the patients are presented in Table 3 . We observed that peripheral arterial occlusions were frequently caused by cardiac pathologies. Cardiac-related reasons were present in 79 cases $(64.75 \%)$ (atrial fibrilation in 46 cases, mitral stenosis in 5 cases, mitral stenosis and atrial fibrillation in 14 cases, prosthetic cardiac valves in 4 cases, myocardial infarction history in 9 cases, endocarditis in 1 case); extracardiac reasons were present in 35 cases $(28.68 \%)$ (atherosclerosis in 24 cases, vascular trauma in 4 cases, abdominal aort aneurism in 7 cases); catheterization in 2 cases $(1.64 \%)$; malignancy in 1 case $(0.81 \%)$; and history of trauma in 3 cases $(2.46 \%)$. In 2 cases $(1.64 \%)$ no reason could be found to explain the thromboembolysis.

Re-embolectomy was performed on 37 patients $(30.32 \%)$ that had ongoing ischemia after an operation. Additional surgical operations were performed on 31 patients $(25.40 \%)$ with ongoing ischemia (Table 2). In 14 of these cases $(11.47 \%)$, patients were treated with fasciotomy due to development of compartment syndrome. Amputation was performed on a total of 9 patients $(7.37 \%)$ who had life-threatening risks; these included 7 patients who had ongoing ischemia despite fasciotomy and had developed a demarcation line, and 2 patients with graft infections. Seven of the amputations were above and 2 were below the knee.
Table 3 Preoperative demographic data

\begin{tabular}{lll}
\hline & $\mathbf{N}$ & $\%$ \\
\hline Age (average) & $54.2 \pm 16.8$ & \\
Sex (male/female) & $71 / 51$ & $58.19 / 41.80$ \\
Accompanying diseases & & \\
Diabetes mellitus & 28 & 22.95 \\
Hypertension & 31 & 25.40 \\
Atrial fibrillation & 60 & 49.18 \\
Congestive heart failure & 9 & 7.37 \\
Rheumatismal heart disease & 23 & 18.85 \\
Cerebrovascular disease & 3 & 2.45 \\
Ischemic heart disease & 13 & 10.65 \\
Onset of complaints & & \\
3-7 days & 91 & 74.59 \\
$>7$ days & 31 & 25.40 \\
Admittance complaints & & \\
Pain & 114 & 93.44 \\
Coldness & 88 & 72.13 \\
Paleness & 94 & 77.04 \\
Sensory loss & 12 & 9.83 \\
Motor deficit & 4 & 3.27 \\
Cyanosis & & \\
\hline & & \\
\hline
\end{tabular}

Incision site infections were observed in 11 of the patients (9.01\%). Infections developed at the amputation site in 2 patients, in the popliteal region below the knee in 2 patients, at abdominal incision site in 1 patient, and 3 patients had graft infections. Two patients with graft infections had amputations performed and the other patients were treated with antibiotherapy. Among the less common complications, myonephropathic metabolic syndrome (reperfusion damage) occurred in 5 patients $(4.09 \%)$, and venous thrombosis in 3 patients $(2.45 \%)$.

Mortality was observed early in the postoperative period in 11 patients $(9.01 \%)$. The cases of mortality comprised patients who were notably older ( $64.3 \pm 5.26$ years), mostly with cardiac problems. However, the age difference between cases with and without mortality was not statistically significant $(P>0.05)$. When patients were admitted to the hospital after 72 hours, mortality was not affected by whether they were admitted between 3 and 7 days or after 7 days $(P>0.05)$. However, morbidity was significantly higher for patients admitted after 7 days $(P=0.027)$. Demographic features related to morbidity and mortality are presented on Table 4. 
Table 4 Demographic data related to morbidity and mortality

\begin{tabular}{lll}
\hline & N & $\%$ \\
\hline Second time embolectomy & 37 & 30.32 \\
Third time embolectomy & 9 & 7.37 \\
Complications & & \\
Fasciotomy & 14 & 11.47 \\
Amputation & 9 & 7.37 \\
Infection & II & 9.01 \\
Myonephropathic metabolic syndrome & 5 & 4.09 \\
Venous thrombosis & 3 & 2.45 \\
Mortality & II & 9.01 \\
Causes of mortality & & \\
Myocardial infarction & 3 & 2.45 \\
Congestive heart failure & 2 & 1.63 \\
Cerebral emboli & I & 0.81 \\
Kidney failure & I & 0.81 \\
Multiorgan failure & 2 & 1.63 \\
Arrhythmia & I & 0.81 \\
Gastrointestinal bleeding & I & 0.81 \\
\hline
\end{tabular}

\section{Discussion}

We analyzed patients admitted to our clinic with acute arterial occlusion who have been operated on in the last 5 years. Delayed use of embolectomy on the extremity with ischemia is still controversial. However, it has been gaining acceptance. Studies in which clinical and pathological data of late arterial embolectomies are investigated have shown that there are four major factors for successful treatment: 1) relatively less damage on arterial intima; 2) thrombus not adhering to intima and no secondary thrombus on intima; 3 ) patent distal arterial tree despite embolization; and 4) presurgical treatment with anticoagulants. When these factors are maintained, adequate circulation can be achieved in the extremities of patients with the use of delayed embolectomy. ${ }^{4}$

Critical leg ischemia is defined as a sudden decrease in leg perfusion, which threatens viability of the extremity. This condition not only results in local ischemia, but also to a pathology that can lead to systemic complications. It is the reason for $10 \%$ to $15 \%$ of surgeries performed in vascular surgery clinics and involves $5 \%$ to $7 \%$ of patients admitted to these clinics with vascular symptoms. ${ }^{5}$

Despite the improved intensive care and surgical conditions, mortality rates remain high. ${ }^{6}$ Mortality and morbidity risks persist even when the reason for acute ischemic condition is eliminated and reperfusion is attained. When surgical intervention is delayed, these risks increase. ${ }^{7}$ Approximately a hundred years have passed since the first successful embolectomy performed by Georges Labey in 1911. ${ }^{8}$ The embolectomy catheters devised by Fogarty have facilitated this operation and increased its success. ${ }^{9}$

Our classical knowledge states that the earlier the embolectomy (especially when it is within the first 8 hours), the better the result. However, cases of successful embolectomies performed a few days after an acute occlusion have also been reported. ${ }^{2,10-12}$ Eliot et $\mathrm{al}^{2}$ showed that for patients with arterial emboli, a delay of more than 8 hours increases ischemic complications, but when the delay exceeds 7 days, the occurrence of complications decreases.

On the other hand, Blaisdell et $\mathrm{al}^{13}$ findings contradict those of Eliot and suggests that a single high-dose heparin therapy course be employed (starting with a 20,000 U bolus and continuous perfusion of 2000 to $4000 \mathrm{U} / \mathrm{h}$ ). According to his view, embolectomy should be performed only on patients with less than 8 hours of ischemia, who are low risk. Cardiac diseases, most commonly mitral narrowness and atrial fibrillation, are the reason for $80 \%$ to $90 \%$ of acute arterial emboli. Embolus is found on the left ventricle apical thrombus, which forms after anterior transmural infarction, at a rate of 5\%. Cardiac mixoma, mechanical heart valves, and grafts are other possible reasons for emboli. ${ }^{14,15}$ Farshad et $\mathrm{al}^{16}$ stated that $10 \%$ to $15 \%$ of emboli as not cardiac-related. Cranley et al ${ }^{17}$ could not find the cause for emboli in $10 \%$ of the cases. However, in our study, the causes for the emboli were $64.75 \%$ cardiac, $28.68 \%$ extracardiac, and $9.04 \%$ other reasons; and, unlike Cranley et al, we could not find the reason for emboli in only 2 cases $(1.63 \%)$.

Compartment syndrome caused by reperfusion after embolectomy must be carefully assessed. Early fasciotomy is required to prevent ischemia and complications that may occur. The time between the onset of ischemia and treatment, the cause of embolization, localization of the emboli, and accompanying pathologies are reported to be important for therapeutic success. ${ }^{18}$

Free oxygen radicals, which emerge after re-establishment of blood flow in an extremity that has remained ischemic for a long time, interact with endothelium and neutrophils, and rapidly increase lipid peroxidation, resulting in many local and systemic affects. Cellular swelling, edema, toxin and myoglobulin release, accompanied by the effects of free oxygen radicals may cause systemic damages such as acute kidney failure, lung edema, sudden onset of adult respiratory distress syndrome and liver shock. Even when extremity reperfusion has been completely restored by removal of the underlying cause of the acute ischemic condition, a chain of events may result in loss of the extremity, acute kidney 
and respiratory failure, or functional deterioration in tissues such as heart, intestine, brain or spleen. ${ }^{19}$ This "reperfusion damage", or "myonephrotic metabolic syndrome" as suggested by Haimovici, is the main cause of mortality and morbidity especially in acute cases treated late. ${ }^{20}$

In various studies, systemic organ damage has been shown to appear as a result of ischemia in the skeletal muscle after 6 to 8 hours of ischemia and as a result of the production of ischemic metabolites, myoglobulinemia and myoglobulinurea, after revascularization. ${ }^{19-22}$ Aune et $\mathrm{al}^{23}$ reported that both serious cardiac disease and reperfusion damage increase mortality in cases of embolism. In our study, 5 patients developed myonephrotic metabolic syndrome by production of ischemic metabolites, and by myoglobinemia and myoglobulinurea, after revascularization. However, we were prepared for this complication and had taken the necessary precautions and immediately started dialysis. Among these 5 patients, only 1 was lost.

The amputation rate following operations undertaken during the first 12 hours is reported in the range of $2.1 \%$ to $5.9 \%$; but the rate increases to $39.2 \%$ after 12 hours. ${ }^{16,17}$ Mortality rates have reported as $12.5 \%$ within 12 hours and $37.7 \%$ thereafter. ${ }^{24}$ Hight et $\mathrm{al}^{25}$ analyzed 11 different series between 1954 and 1974 and determined an amputation rate of $4 \%$ to $48 \%$ and a mortality rate of $14 \%$ to $50 \%$. In a study by Yangni et $\mathrm{al}^{26}$ that included 24 patients, the amputation rate was reported as $29.2 \%$ and the mortality rate as $29.2 \%$. In another study, the amputation rate of arterial embolectomies beyond 24 hours was reported to be $11.4 \% .^{15}$

In our study, fasciotomy was performed for $11.47 \%$ of the patients, those who had developed compartment syndrome. For 7 patients who had ongoing ischemia despite fasciotomy and who had developed a demarcation line and for 2 patients with graft infections, amputation was performed (altogether $7.37 \%$ ) because of life-hreatening risks. Although mortality rates of patients who have received embolectomy 12 hours later is reported to be high in the literature, only 11 patients died $(9.01 \%)$ in our study, mostly older (average age, $64.3 \pm 5.26$ years) patients, mostly with cardiac problems. In addition, we think that postoperative heparin and dextran 40 infusion for at least 3 days is the reason for the lower morbidity and mortality rates observed in our study cohort.

Early diagnosis and treatment of acute arterial emboli play an important role in morbidity and mortality. Considering our morbidity and mortality rates, we think that performing an additional surgical operation in acute leg ischemia would be appropriate even if a week has passed.

\section{Conclusion}

We believe that late embolectomies of acute leg ischemia increase blood flow in the extremity and reduce the number of amputations required. We also think it is advantageous to give the patient a chance by performing embolectomy, even as late as a week after diagnosis of ischemia.

\section{Disclosure}

The authors declare no conflicts of interest.

\section{References}

1. Braithwaite BD, Davies B, Birch PA, Heather BP, Earnshaw JJ. Management of acute leg ischemia in the elderly. Br J Surg. 1988; $85: 217-220$

2. Elliot JP, Hageman JH, Szilagyi DE, Ramakrishnan V, Bravo JJ, Smith RF. Arterial embolization: Problems of source, multiplicty, recurrence and delayed treatment. Surgery. 1980;88:833-845.

3. Rutherford RB, Baker JD, Ernst C, et al. Recommended standards for reports dealing with lower extremity ischemia. J Vasc Surg. 1997;26:517-538.

4. Haimovici H, Ascer E, Holier HL, Strandness DE, Towne JB. Peripheral arterial aneurysms. In: Haimovici's Vascular Surgery. Principal and Techniques (eds: Haimovici H), 4th ed. Blackwell Science Cambridge 1996:893-910.

5. Ouriel K. Acute limb ischemia. In: Vascular surgery. Rutherfort RB ed 6th ed. Philadelphia: Elsevier; 2005:959-986.

6. Patel N, Sacks D, Patel RI, et al. SCVIR reporting standards for the treatment of acute limb ischemia with use of transluminal removal of arterial thrombus. $J$ Vasc Interv Radiol. 2001;12:559-570.

7. Hobson RW II, Milazzo VJ, Duran WN. Pathophysilogy of skeletal muscle ischemia-reperfusion injury. In: Haimovici's Vascular Surgery Principal and Techniques. Haimovici $\mathrm{H}$ ed. 4th ed. Cambridge: Blackwell Science; 1996:497-508.

8. Cranley JJ, Krause RJ, Strasser ES, Hafner CD, Fogarty TJ. Peripheral arterial embolism: Changing concepts. Surgery. 1964;55: 57-63.

9. Fogarty TJ. Management of arterial emboli. Surg Clin North Am. 1979;59:749-753.

10. Shifrin EG, Anner H, Eid A, Romanoff H. Practice and theory of 'delayed' embolectomy. J Cardiovasc Surg. 1986;27:553-556.

11. Cambria RP, Ridge BA, Brewster DC, Moncure AC, Darling RC, Abbott WM. Delayed presentation and treatment of popliteal artery embolism. Ann Surg. 1991;214:50-55.

12. Jarrett GC, Dacumos GC, Crummy AB, et al. Late apparance of arterial emboli: diagnosis and management. Surgery. 1979;86: 898-905.

13. Blaisdell FW, Steele M, Allen RE: Management of acute lower extremity arterial ischemia due to embolism and thrmbosis. Surgery. 1978;84:822-825.

14. Erentug V, Mansuroglu D, Bozbuga NU, et al. Treatment of acute arterial occlusions. [in Turkish]. Turkish J Thorac Cardiovasc Surg. 2003;11:236-239.

15. Karapolat S, Dag O, Abanoz M, Aslan M. Arterial embolectomy: a retrospective evaluation of 730 cases over 20 years. Surg Today. 2006;36:416-419.

16. Abir F, Barkhordorian B, Sumpio BE. Non cardiac vascular complications of coronary bypass procedures: A review. Int $J$ Angiol. 2004;13:1-6.

17. Cranley JJ, Krause RJ, Strasser ES, Hafner CD, Fogarty TJ. Peripheral arterial embolism: Changing concepts. Surgery. 1964;55:57-63.

18. Panetta T, Thompson JE, Talkington CM, Garrett WV, Smith BL. Arterial embolectomy: A 34-year experience with 400 cases. Surg Clin North Am. 1986;66:339-353. 
19. Haimovici H. Metabolic complications of acute arterial occlusions and skeletal muscle ischemis: Myonephropatic-metabolic syndrome. In: Haimovici's Vascular Surgery. Principal and Techniques. Haimovici H ed. 4th ed. Cambridge: Blackwell Science; 1996: 509-530.

20. Parrino PE, Laubach VE, Gaughen JR Jr, et al. Inhibition of inducible nitric oxide synthase after myocardial ischemia increases coronary flow. Ann Thorac Surg. 1998;66:733-739.

21. Duprez D. Naturel history and evolution of peripheral obsturictive arterial disease. Int Angiol. 1992;11:165-168.

22. Stoney RJ, Thompson RW, Nelken NA. Surgical recanaliation of occluded peripheral arteries. Surg Clin North Am. 1992;72:749-756.
23. Annue S, Trippestad A. Operative mortality and Long term survival of patients operated on for acute lower limb ischemia. Eur J Endovasc Surg. 1998;15:143-146.

24. Taviloğlu K, Günay K, Asaoğlu O, Güloğlu R, Kurtoğlu M. Is primary amputation required in peripheral arterial occlusion cases that are admitted to the clinic with 12-hour delay? [in Turkish]. Turkish J Vasc Surg. 1995;4:91-96.

25. Hight DW, Tilney NL, Couch NP: Changing clinical trends with arterial emboli. Surgery. 1976;79:172-176.

26. Yangni AH, Adoubi A, Adoh M, Yapobi Y, Coulibaly AO. Acute nontraumatic limb ischemia. West Afr J Med. 2006;25:101-104.

\section{Publish your work in this journal}

Vascular Health and Risk Management is an international, peerreviewed journal of therapeutics and risk management, focusing on concise rapid reporting of clinical studies on the processes involved in the maintenance of vascular health; the monitoring, prevention and treatment of vascular disease and its sequelae; and the involvement of metabolic disorders, particularly diabetes. This journal is indexed on PubMed Central and MedLine. The manuscript management system is completely online and includes a very quick and fair peer-review system, which is all easy to use. Visit http://www.dovepress.com/ testimonials.php to read real quotes from published authors. 